\title{
Relationship between supramaximal flow during cough and mortality in motor neurone disease
}

\author{
M.B. Chaudri*, C. Liü, R. Hubbard", D. Jefferson\#, W.J. Kinnear*
}

Relationship between supramaximal flow during cough and mortality in motor neurone disease. M.B. Chaudri, C. Liu, R. Hubbard, D. Jefferson, W.J. Kinnear. (C)ERS Journals Ltd 2002.

ABSTRACT: The main function of cough is clearance of intrathoracic airways. A normal cough is characterized by a transient increase in expiratory flow above the maximal flow-volume loop envelope, known as cough "spikes". They may be absent in patients with motor neurone disease. The relationship between cough pattern, pulmonary function and survival was studied.

Fifty-three patients were recruited ( 25 bulbar). Vital capacity, maximal inspiratory and expiratory mouth pressures and cough flow/volume curves were performed on all patients, and the presence or absence of spikes were recorded. The primary endpoints were mortality or initiation of ventilatory support over a period of 18 months.

Thirty-five patients died over the 18-month period of the study (including the six who were started on noninvasive ventilation). Twelve of the 24 patients with spikes died compared to 23 out of 29 patients without spikes $(p<0.05)$. Patients without spikes were more likely to be bulbar on clinical grounds $(p<0.0001)$ and had poorer lung function.

The results showed an association between the absence of cough spikes and increased mortality. However the main determinants of survival in motor neurone disease are age, vital capacity and inspiratory mouth pressure, and it remains to be shown whether regular monitoring of cough conveys any additional advantage. Eur Respir J 2002; 19: 434-438.
Depts of *Respiratory Medicine and \#Neurology, University Hospital, and 'Dept of Respiratory Medicine, City Hospital Nottingham, UK.

Correspondence: W.J. Kinnear, University Hospital, Derby Road, Nottingham, NG7 2UH, UK.

Fax: 441159707493

E-mail: mazhar.chaudri1@freeserve. co.uk

Keywords: Bulbar function, cough spikes, expiratory muscle weakness, motor neurone disease, survival

Received: September 202000

Accepted after revision September 27 2001

This study was supported financially by the MND Care and Research Centre, Queen's Medical Centre, Nottingham, UK
The cough mechanism plays a protective role in the normal functioning of the respiratory system. It allows clearance of secretions and foreign bodies from the airway and prevents aspiration into the lungs. Effective cough is initiated by inhaling a variable amount of air. Then, contraction of respiratory muscles generates sufficient intrathoracic pressure to cause dynamic compression of the airways. The glottis is opened suddenly and air is forcibly released leading to transient supramaximal flow [1]. This appears as a "spike" [2] on tracings of the maximal expiratory flow volume curve (MEFV; fig. 1a). Spikes are produced by wave-speed flows due to an initial and unstable configuration of the flow-limiting segment [3].

Motor neurone disease (MND) is a progressive neurodegenerative condition, which causes weakness, wasting and fatigue of voluntary muscles. Cough may be impaired in MND for a number of different reasons [4]. Respiratory infection may occur as a consequence of weak cough. Poor lung function may be compromised further, due to exacerbation of respiratory muscle weakness [5] and precipitate respiratory failure [6].

The relationships between cough in MND (as defined by the absence or presence of cough spikes), death and tests of pulmonary function were examined.
The primary endpoints were mortality at 18 months or initiation of noninvasive ventilation.

\section{Methods}

Fifty-three patients were recruited for this study, all of which were drawn from the MND clinic. Each patient satisfied the El Escorial criteria for MND [7]. Ethical approval and written consent were obtained in all cases. Bulbar involvement was defined on clinical grounds by a history of dysphagia, dysarthria or drooling, and signs on examination, of an increased jaw jerk and/or tongue wasting, fasciculation or spasticity.

Measurement of lung function was conducted in the seated position. The best of three results was taken. Nose-clips were applied throughout the course of the procedure. Vital capacity (VC) was recorded by breathing in to total lung capacity (TLC) and blowing out fully via a cylindrical mouthpiece (or flanged one if deemed appropriate) into a pneumotachograph (Fleish \#3) connected to a pressure transducer (SiPLAN Electronic Research, Stratford, UK). The signal was passed through an analogue-todigital converter sampling at $1000 \cdot \mathrm{s}^{-1}$ into an A300 microcomputer (Acorn, Cambridge, UK). 

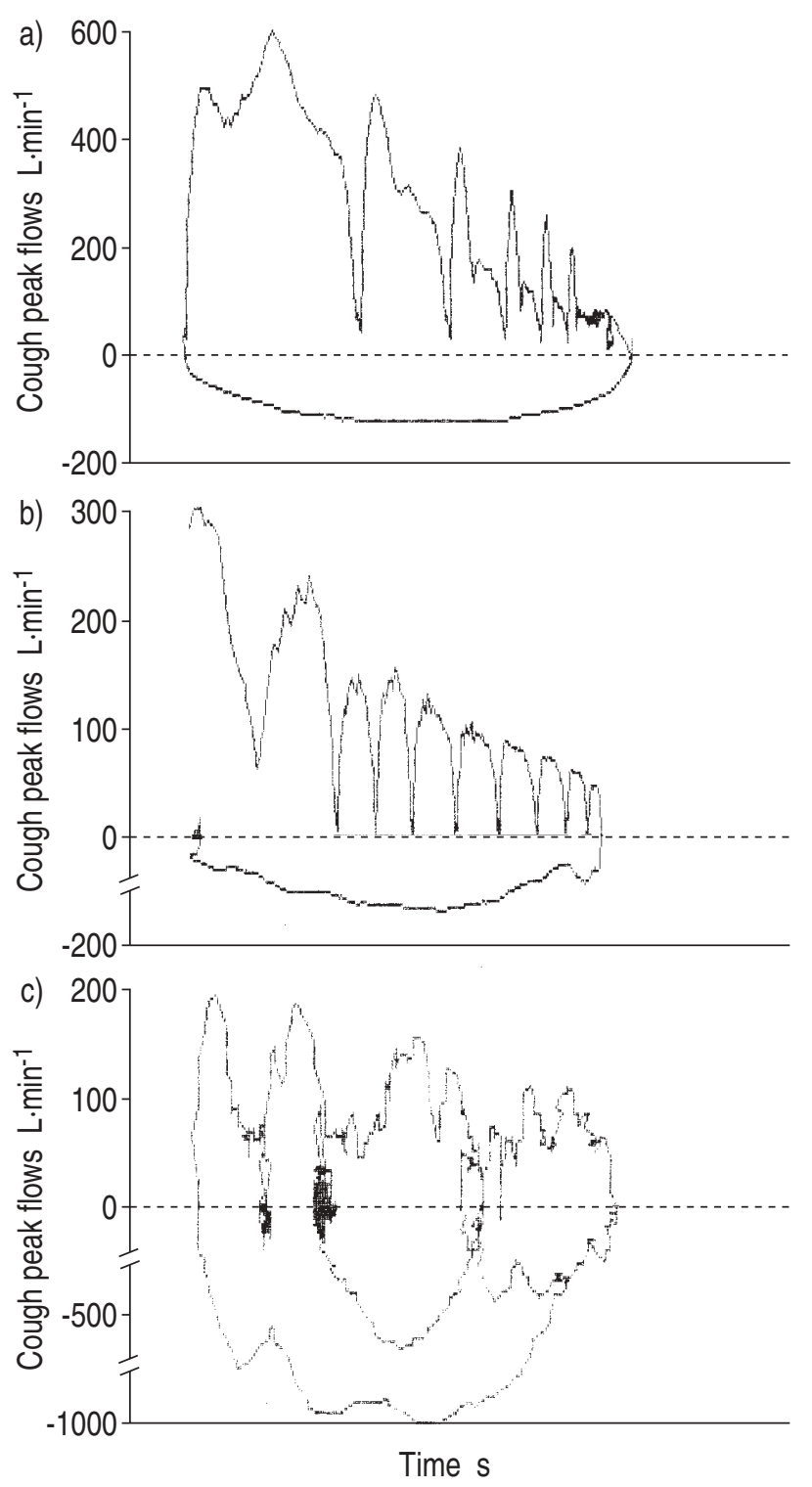

Fig. 1.-a) A series of cough spikes superimposed on the maximal expiratory flow volume curve. b) An example of a patient who was unable to produce cough spikes. c) A grossly distorted cough flow/volume curve in a bulbar patient.

Cough was measured by instructing patients to inspire to TLC and then cough sequentially into the pneumotachograph without taking intervening inhalations. The maximal peak flow rate achieved during cough (CPFR) was recorded and the cough flow/volume curve was superimposed on the MEFV. A single observer analysed the traces "blind" for the presence or absence of cough spikes.

Maximal expiratory mouth pressures were measured by breathing for at least $1 \mathrm{~s}$ through a flanged mouthpiece, attached via a plastic tube to a hand-held meter (Pmax Monitor; PK Morgan, Rainham, Kent, UK). The plastic tube had a 22-gauge leak to prevent glottic closure. The patient was encouraged to blow out as forcefully as possible from TLC with the hands pressed against the cheeks. VC [8] and mouth pressures [9] were expressed as percentage predicted. Maximal inspiratory mouth pressures were performed using the same equipment, except that the patients were instructed to inhale forcefully from residual volume.

Data were analysed with Arcus QuickStat for Windows (Addison Wesley Longman, Cambridge, UK) and STATA version 7 (STATA Corporation, TX, USA). An initial descriptive analysis was performed using the Mann-Whitney test to compare continuous variables and Fisher's exact test to compare categorical variables. In order to determine whether cough was a predictor of survival, a combination of Kaplan-Meier curves and a Cox's proportional hazard model was used. The diagnostics section within STATA was used to confirm the proportional hazards assumption of the Cox models.

\section{Results}

Baseline data are shown in table 1. None of the patients had coexisting lung disease or were on ventilatory support. Twenty-five patients were classified as bulbar on clinical grounds.

Patients were differentiated into two groups: those that did not have cough spikes on the cough flow/ volume curve (group one), and those that did (group two). There were two discernible patterns in group one: five patients had normal-shaped MEFV curves but were unable to generate spikes during cough (fig. 1b). Twenty-four others had distorted curves (fig. 1c), often with oscillations on the inspiratory or expiratory arm, consistent with bulbar involvement [10]. Three of these patients had no bulbar manifestations clinically.

All group two patients had normal MEFV curves and spikes on coughing. They were predominantly nonbulbar although they did include four patients with symptoms or signs of bulbar involvement.

Both groups were well matched for age, sex and disease duration. Group one patients were more likely to be bulbar on clinical grounds and had

Table 1.-Baseline characteristics

\begin{tabular}{lccc}
\hline & $\begin{array}{c}\text { No spikes } \\
\text { (Group one) }\end{array}$ & $\begin{array}{c}\text { Spikes } \\
\text { (Group two) }\end{array}$ & p-value \\
\hline Patients n & 29 & 24 & \\
Age yrs & $60.52 \pm 14.21$ & $59.92 \pm 10.65$ & NS \\
Sex M:F & $20: 9$ & $22: 2$ & NS \\
Disease duration & $35.15 \pm 32.48$ & $27.86 \pm 22.75$ & NS \\
$\quad$ months & & & \\
Bulbar & 21 & 4 & $\#$ \\
BMI kg·m & $22 \pm 3.33$ & $25.63 \pm 3.73$ & $* * *$ \\
VC \% pred & $61.62 \pm 23.6$ & $76 \pm 20.95$ & $*$ \\
CPFR L·min -1 & $181.86 \pm 117.62$ & $337.33 \pm 105.22$ & $\#$ \\
MIP \% pred & $16.63 \pm 11.14$ & $36.92 \pm 26.07$ & $* * *$ \\
MEP \% pred & $19.83 \pm 13.21$ & $45.67 \pm 27.37$ & $\#$ \\
\hline
\end{tabular}

Data are presented as mean \pm SD unless otherwise stated. M: male; F: female; BMI: body mass index; VC: vital capacity; CPFR: cough peak flow rate; MIP: inspiratory mouth pressure; MEP: expiratory mouth pressure; NS: nonsignificant. *: $\mathrm{p}<0.05$; ***: $\mathrm{p}<0.001 ;{ }^{\#}: \mathrm{p}<0.0001$. 


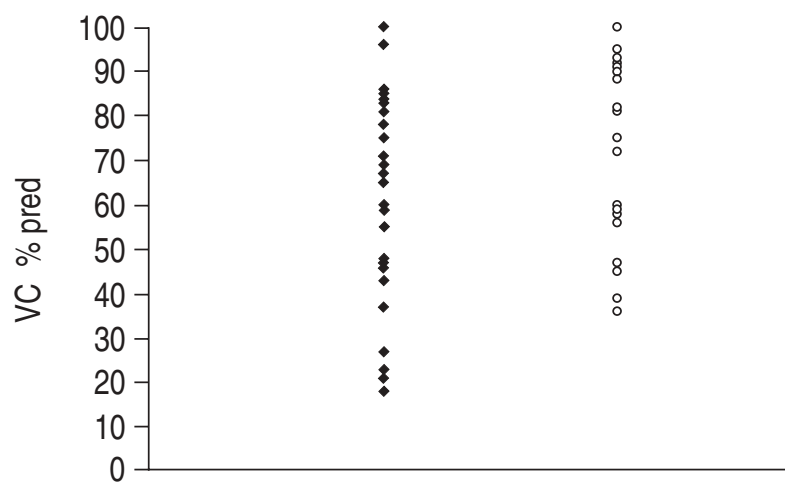

Fig. 2.-Comparison of vital capacity (VC) \% predicted (\% pred) in patients without cough spikes $(\bullet)$ and those with cough spikes $(\bigcirc)$.

lower mean body mass index scores. Group two patients had significantly better lung function tests (see fig. 2 for comparison of individual values of $\mathrm{VC}$ ), although there was considerable overlap between the two groups. The minimum values obtained in group two for VC, inspiratory mouth pressure (MIP) and expiratory mouth pressure (MEP) were 36, $7\left(8 \mathrm{cmH}_{2} \mathrm{O}\right)$ and $14 \%\left(19 \mathrm{cmH}_{2} \mathrm{O}\right)$ respectively. Only one group 1 patient managed an MEP value $>60 \%$, and none had a MIP $>41 \%$. MIP and MEP were closely related in the majority of the patients, irrespective of cough pattern (Spearman's correlation coefficient (rho) $=0.77, \mathrm{p}<0.0001,95 \%$ confidence interval $(\mathrm{CI})=0.63-0.87)$.

A total of 35 patients died within 18 months of examination (table 2). Median survival was 301 days. The cause of death was respiratory failure or lower respiratory tract infection in all cases. Six patients were commenced on noninvasive ventilation but one was unable to tolerate it. None of them were alive at 18 months. Patients who died tended to be older and had worse lung function although, again, there was a large degree of overlap.

Table 2. - Comparison of baseline data in patients who were dead or alive at 18 months

\begin{tabular}{|c|c|c|c|}
\hline & Dead & Alive & p-valu \\
\hline Patients $n$ & 35 & 18 & \\
\hline Age yrs & $63.6 \pm 11.57$ & $53.72 \pm 12.26$ & $* *$ \\
\hline Sex M:F & $27: 8$ & $15: 3$ & NS \\
\hline $\begin{array}{l}\text { Disease duration } \\
\text { months }\end{array}$ & $30.06 \pm 28.97$ & $35.29 \pm 28.08$ & NS \\
\hline Bulbar & 19 & 6 & NS \\
\hline $\mathrm{BMI} \mathrm{kg} \cdot \mathrm{m}^{-2}$ & $23.13 \pm 3.80$ & $24.97 \pm 4.06$ & NS \\
\hline $\mathrm{VC} \%$ pred & $61.91 \pm 21.57$ & $80.28 \pm 22.08$ & $* *$ \\
\hline $\mathrm{CPFR} \mathrm{L} \cdot \mathrm{min}^{-1}$ & $214.89 \pm 131.26$ & $324.94 \pm 116.24$ & $* *$ \\
\hline MIP \% pred & $20.13 \pm 18.43$ & $37.83 \pm 24.32$ & $* *$ \\
\hline MEP $\%$ pred & $27.03 \pm 21.68$ & $42.28 \pm 27.66$ & $*$ \\
\hline Spikes & 12 & 12 & $*$ \\
\hline
\end{tabular}

Data are presented as mean \pm SD unless otherwise stated. M: male; F: female; BMI: body mass index; VC: vital capacity; CPFR: cough peak flow rate; MIP: inspiratory mouth pressure; MEP: expiratory mouth pressure; NS: nonsignificant. *: $\mathrm{p}<0.05 ; * *: \mathrm{p}<0.01$

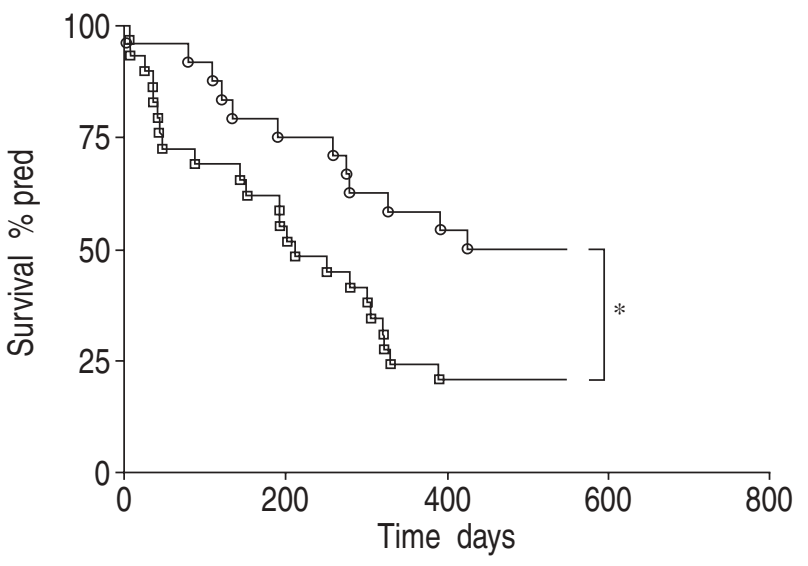

Fig. 3. - Kaplan-Meier curve comparing survival \% predicted ( $\%$ pred) in patients with spikes $(\bigcirc)$ and those without spikes $(\square)$. $*: \mathrm{p}<0.05$.

Kaplan-Meier curves were constructed comparing groups one and two (fig. 3). Patients with spikes had a significantly greater chance of being alive at 18 months $(\mathrm{p}<0.05)$. The univariate hazard ratio for the Cox model showed an association between survival and the presence of spikes (hazard ratio 0.44 , $\mathrm{p}<0.02$, 95\% CI 0.22-0.88). However using Cox's multivariate model, the most important factors for survival were age, followed by VC and MIP, and after adjusting the model for these variables the presence of spikes per se had no significant influence on survival (table 3 ).

\section{Discussion}

The results show that 18 -month survival was significantly reduced in the nonspike group. Patients who were unable to generate cough spikes had significantly poorer lung function than those who could.

Considerable overlap of respiratory function between patients who demonstrated cough spikes and those who did not was found. Even patients with very poor results could generate spikes; for example in three patients in group two both MIP and MEP were less than $20 \%$ predicted. Patients with inspiratory muscle weakness have a smaller VC and cannot achieve their premorbid TLC. Therefore, it could be argued that it is simply more difficult to

Table 3. - Cox's proportional hazards model for survival

\begin{tabular}{lccc}
\hline & Hazard ratio & p-value & $95 \%$ CI \\
\hline Spikes & 0.99 & 0.98 & $0.30-3.24$ \\
Age & 1.04 & 0.04 & $1.00-1.08$ \\
Sex & 0.85 & 0.75 & $0.30-2.40$ \\
Peak flow & 1.00 & 0.64 & $0.99-1.00$ \\
MIP \% & 0.98 & 0.33 & $0.95-1.02$ \\
VC \% & 0.98 & 0.15 & $0.96-1.01$ \\
\hline
\end{tabular}

CI: confidence interval; MIP: mean inspiratory pressure; VC: vital capacity. 
detect cough spikes in patients with inspiratory muscle weakness. However, the close relationship between inspiratory and expiratory muscle strength observed in the present study argues in favour of the simpler explanation that MND tends to affect inspiratory and expiratory muscles equally.

It is not known whether the lower MIP and MEP results in both groups were an accurate reflection of actual respiratory muscle weakness. These tests are volitional and despite encouragement, some patients may have made submaximal effort. Furthermore, air leaks may arise due to orofacial weakness, although the latter is more likely to be a feature of group one patients (who were mainly bulbar).

In contrast to these results, muscular dystrophy patients with expiratory muscle weakness were unable to produce cough spikes below an MEP threshold of $60 \mathrm{cmH}_{2} \mathrm{O}$ [11]. Others have found cough to be ineffective below an MEP of $40 \mathrm{cmH}_{2} \mathrm{O}$ [12]. PoLKeY et al. [13] were able to show threshold values using cough and twitch gastric pressures but not MEP. The former two did not correlate well with MEP, which could be falsely low, while the other measures remained high. However, in a trial of normal curarized volunteers, MEP was closely correlated with intrapleural pressure [14]. Flow transients were preserved until MEP was about 20\% pred.

The ability to coordinate cough effectively may be the differentiating factor between two sets of patients with equally poor lung function. Absence of spikes in group one patients may have occurred partly due to dyspraxia or instability of upper airway muscles during cough. Most of them had abnormal cough or MEFV curves, characterized by flow limitation or oscillations. A few non-bulbar patients had similar findings, implying insidious bulbar dysfunction, which has been reported previously [15].

Vocal-cord dysfunction may also play a role. Paradoxical vocal-cord closure in expiration has been described in MND [13]. In one series, 30\% of bulbar patients had impaired vocal-cord abduction, which was usually bilateral [16]. This may lead to increased airflow resistance during the expulsive phase of cough. Patients with vocal-cord palsy due to a variety of causes have abnormal cough patterns and take longer to reach maximum CPFR [17]. Conversely, failure of paralysed vocal cords to appose fully during the compressive phase may lead to air leakage, limiting the rise in intrathoracic pressure and reducing dynamic airway compression.

In this study, patients with cough spikes were significantly more likely to be alive 18 months after baseline tests. This is consistent with the hypothesis that a weak cough leads to inability to clear the airway effectively and hence, increases susceptibility to pulmonary infection. It has been suggested that noninvasive cough aids such as mechanical insufflation-exsufflation devices can augment cough and remove secretions, thus prolonging survival in selected patients with MND [18]. Their utility has been also described in severe bulbar disease [19].

However, the main determinant of survival appears to be lung function, notably VC and MIP, but not MEP. The former is consistent with previous studies, which have shown that lower forced vital capacity [20] and a more rapid rate of decline of pulmonary function [21-23] are associated with shorter survival. Although MEP was not related to survival, it correlated closely with MIP, suggesting that inspiratory and expiratory muscle weakness occur simultaneously. Age has previously been identified as a negative prognostic factor in several studies [20-24].

This study was limited by the fact that the authors did not assess intrapleural or gastric pressures, as MIP and MEP can be unreliable. However, the authors feel the former investigations are probably inappropriate in bulbar patients and the role of the latter has not yet been established. The numbers that were studied were small, and it would have been informative to have followed-up patients for a longer period of time.

In summary, loss of cough spikes is indicative of ineffective cough and can be attributed to respiratory muscle weakness and/or bulbar dysfunction. Such patients have a higher mortality rate because of poorer lung function. Although impaired cough is not a prognostic factor, it may have a role in identifying patients that need to be monitored more closely, and who can then be treated promptly in the event of deterioration.

\section{References}

1. Knudson RJ, Mead J, Knudson DE. Contribution of airway collapse to supramaximal expiratory flows. J Appl Physiol 1974; 36: 653-667.

2. Beardsmore CS, Wimpress SP, Thomson AH, Patel HR, Goodenough P, Simpson H. Maximum voluntary cough: an indication of airway function. Bull Eur Physiopathol Respir 1987; 23: 465-472.

3. Pedersen $\mathrm{OF}$, Lyager S, Ingram RH Jr. Airway dynamics in transition between peak and maximal expiratory flow. J Appl Physiol 1985; 59: 1733-1746.

4. Hadjikoutis S, Wiles CM, Eccles R. Cough in motor neuron disease: a review of mechanisms. $Q \mathrm{~J} \mathrm{Med}$ 1999; 92: 487-494.

5. Mier-Jedrzejowicz A, Brophy C, Green M. Respiratory muscle weakness during upper respiratory tract infections. Am Rev Respir Dis 1988; 138: 5-7.

6. Kreitzer SM, Saunders NA, Tyler HR, Ingram RH Jr. Respiratory muscle function in Amyotrophic Lateral Sclerosis. Am Rev Respir Dis 1978; 117: 437-447.

7. World Federation of Neurology Research Group on neuromuscular diseases. Subcommitee on motor neurone diseases "El Escorial World Federation of Neurology Criteria for the diagnosis of Amyotrophic Lateral Sclerosis". J Neurol Sci 1994; 124: 96-107.

8. Quanjer PH, Tammeling GJ, Cotes JE, Pedersen OF, Peslin R, Yernault JC. Standardised lung function testing - lung volumes and forced ventilatory flows. Eur Respir J 1993; 6: Suppl. 16, 24.

9. Bruschi C, Cerveri I, Zoia MC, et al. Reference values of maximal respiratory mouth pressures: A population-based study. Am Rev Respir Dis 1992; 146: 790-793.

10. Wincken W, Elleker G, Cosio MG. Detection of upper airway muscle involvement in neuromuscular 
disorders using the flow-volume loop. Chest 1986; 90: 50-57.

11. Szeinberg A, Tabachnik E, Rashed N, et al. Cough capacity in patients with muscular dystrophy. Chest 1988; 94: 1232-1235.

12. O'Donohue WJ, Baker JP, Bell GM. Respiratory failure in neuromuscular disease: management in a respiratory intensive care unit. JAMA 1976; 235: 733735.

13. Polkey MI, Lyall RA, Green M, Leigh PN, Moxham J. Expiratory muscle function in amyotrophic lateral sclerosis. Am J Respir Crit Care Med 1998; 158: 734 741.

14. Arora NS, Gal TJ. Cough dynamics during progressive expiratory muscle weakness in healthy curarized subjects. J Appl Physiol 1981; 51: 494498.

15. Briani C, Marcon M, Ermani M, et al. Radiological evidence of subclinical dysphagia in motor neuron disease. J Neurol 1998; 245: 211-216.

16. Hillel AD, Miller R. Bulbar amyotrophic lateral sclerosis: patterns of progression and clinical management. Head \& Neck 1989; 11: 51-59.

17. Murty GE, Lancaster P, Kelly PJ. Cough intensity in patients with a vocal cord palsy. Clin Otolaryng 1991; 16: 248-251.

18. Bach JR. Amyotrophic lateral sclerosis: predictors for prolongation of life by noninvasive respiratory aids. Arch Phys Med Rehabil 1995; 76: 828-832.

19. Hanayama K, Ishikawa Y, Bach JR. Amyotrophic lateral sclerosis: successful treatment of mucous plugging by mechanical insufflation-exsufflation. Am J Phys Med Rehabil 1997; 76: 338-339.

20. Stambler N, Charatan M, Cederbaum J and the ALS CNTF Treatment Study Group. Prognostic indicators of survival in ALS. Neurology 1998; 50: 66-72.

21. Haverkamp LJ, Appel V, Appel SH. Natural history of amyotrophic lateral sclerosis in a database population. Brain 1995; 118: 707-719.

22. Ringel SP, Murphy JR, Alderson MD, et al. The natural history of amyotrophic lateral sclerosis. Neurology 1993; 43: 1316-1322.

23. Fallat RJ, Jewitt B, Bass M, Kamm B, Norris FH Jr. Spirometry in amyotrophic lateral sclerosis. Arch Neurol 1979; 36: 74-80.

24. Rosen AD. Amyotrophic lateral sclerosis: clinical feature and prognosis. Arch Neurol 1978; 35: 638-642. 